\title{
Adjustable Sutures
}

\author{
PETER FELLS
}

London

Strabismus surgery has long been the Cinderella of ophthalmic operations and one reason for this has been the impossibility of predicting the results using conventional, fixed sutures. Most surgeons ${ }^{1.2 .3 .4}$ have found that using adjustable sutures has given better results in terms of both immediate alignment and long term stability of the eyes. Jampolskys re-introduced adjustable suture strabismus surgery in 1974 although the technique had been used at least fifty years earlier. I first addressed this Congress on this topic in $1981^{6}$ employing the two stage operation under general anaesthesia with subsequent adjustment the next morning under local anaesthesia. I shall briefly describe this two stage procedure which also serves as introduction to the main theme-that of the one stage operation under topical, local anaesthesia. ${ }^{7.8}$

All adults listed for strabismus surgery should be considered for adjustable sutures. Any doubts about patient compliance may be tested by instilling amethocaine eyedrops to one eye and then moving the globe with either non-toothed forceps or a cotton bud stick.

The general anaesthetic must leave the patient fully alert at the time of adjustment. This means that care must be taken over the choice of both pre- and post-operative medications as well as keeping the patient as 'light' as possible during the operation.

My technique aims to keep full muscle width and avoid bulky, complex knots uncovered by conjunctiva. Coloured 6-0 Vicryl or Dexon sutures on spatulate needles are excellent. Any of the 4 rectus muscles may be operated on, but not more than 2 muscles of the same eye at a time. Usually the sliding sutures are kept for recession procedures since their use in resections entails excising more of the muscle than would otherwise be necessary to allow adjustment either further forwards or backward.

The conjunctiva is opened $2 \mathrm{~mm}$ behind the normal muscle insertion. The double-armed Vicryl suture is securely locked into each edge of the rectus muscle prior to its disinsertion and the needle then passed from behind forwards into the stepped edge of the original insertion. This is repeated, making a Z-shaped attachment of each half of the muscle through a 1.5 to $2 \mathrm{~mm}$ scleral track which provides just the right amount of friction to hold the muscle in the required position and yet traction can easily advance the muscle as necessary (Fig 1). A temporary knot is tied over a squint hook, with a single throw being locked by a half bow (Fig. 2). The muscle is left recessed the number of millimetres dictated by conventional surgery so that the surgeon must be prepared either to pull forwards or further recess it. The two ends of the conjunctival opening are sutured with 6-0 Vicryl and the eye padded.

Next morning the eye should be cleaned and left uncovered for at least ten minutes before suture adjustment to allow the patient to discover where the areas of diplopia are. Amethocaine drops are instilled and adjustment carried out with the patient seated and an assistant holding the lids with cotton bud sticks. Any vertical diplopia is corrected first and then horizontal. The patient must be checked with glasses at both near and distance. If necessary, new glasses without any built-in prism should have been obtained prior to the surgery. Adjustments are performed to give control in the primary position with a good field of binocular fixation and adequate ocular rotations. With certain conditions, e.g. dysthyroid eye disease, undercorrection of the strabismus is best because the 

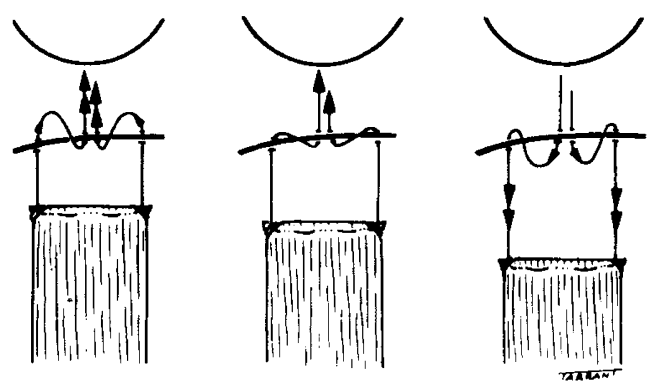

Fig. 1. The central figure shows the Z-shaped track taken by the suture on each side passing through the original muscle insertion.

On the left is shown one way of pulling the muscle further forwards by first enlarging the loops in front of the insertion and then by traction on the closely emergent sutures.

On the right is the method for further recession of the muscle. First the loops behind the insertion are enlarged and then the patient is encouraged to look in the direction of muscle action while the surgeon holds the eye firmly by the original insertion. The muscle contracts and takes up the slack in the suture, increasing the recession.
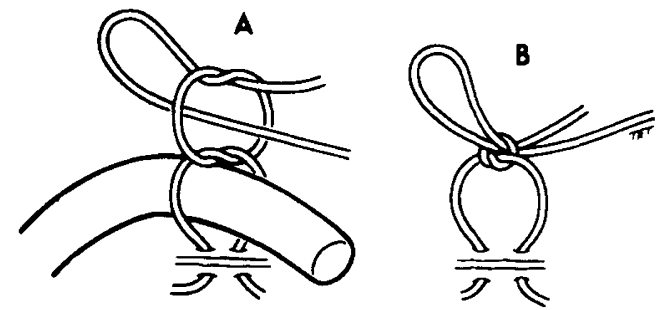

Fig. 2. The adjustable suture is tied temporarily over a squint hook and the half bow loop pulled down tightly before sliding out the hook. When carrying out adjustment next day it is much easier to open this knot fully and adjust as required than if the temporary knot had been tied flush with the sclera.

antagonist of the restricted muscle has become very strong and this reduces the risk of late overcorrection.

What can go wrong in these operations? The patient may not co-operate with the adjustment the next day despite a satisfactory response to the pre-operative compliance test. Only further explanations and a confident attitude of the surgeon can be used to enable the patient to go through with the second stage of adjustment. Very rarely the suture may break during adjustment and this is overcome by virtually re-doing the operation under local anaesthesia. The logical consequence is to plan to do the original procedure under local anaesthesia together with the adjustment in one stage.

For the whole operation under local anaesthesia premedication is with propranolol (Inderal) 40 mgms by mouth or temazepan 20 mgms orally; 2 drops of 1 in 10,000 adrenaline for vasoconstriction and then amethocaine $1 \%$ every two minutes for four to five applications. I use $\times 2$ telescopic operating glasses because the microscope light is too bright for the patient unless a retrobulbar injection has been used and, of course, that must be avoided as it would alter muscle action. Talking to the patient maintains his confidence but means that the surgeon must be so sure of his technique that he can operate virtually in automatic'. Hence the importance of developing a foolproof technique first when operating under general anaesthesia. Once the conjunctiva has been opened the rest of the procedure is pain free provided that the muscle is not suddenly jerked or stretched. Sutures can be inserted, muscles cut, and bipolar diathermy used as usual. Vertical muscle adjustment may be performed with the patient supine, but for horizontal correction he must sit up, glasses worn and tested at near and distance. Only at the time of final conjunctival closure are more amethocaine drops needed and non-toothed forceps used.

My original indications for one-stage surgery under topical anaesthesia were in patients where general anaesthesia was contraindicated by a history of pulmonary embolism, or severe obesity, or who had had a bad experience with general anaesthesia. The one essential requirement for local anaesthesia is that the patient can voluntarily rotate the eye into a position allowing proper access to the muscle. Other desirable features are fusion potential, that the muscle(s) has not had previous surgery, not more than two muscles of the same eye need repositioning and that the patient can lie flat on his back for up to one hour.

I now find that where a single muscle needs recession, as in dysthyroid eye disease, local anaesthesia is the method of choice. The extra confidence gained by the surgeon operating under local anaesthesia further improves his ability to do suture adjustment in the twostage procedures. 


\section{References}

${ }^{1}$ Lee J, O'Day J, Fells P: Early experience with adjustable squint surgery at Moorfields Eye Hospital with long term follow up. Trans Ophthalmol Soc UK 1985, 104: 662-74.

${ }^{2}$ Rosenblaum AL, Metz HS, Carlson M, Jampolsky AL: Adjustable rectus muscle recession surgery. Arch Ophthalmol 1977, 95: 817-20.

${ }^{3}$ Lennerstrand G: Adjustable sutures in strabismus surgery. Acta Ophthalmol 1982, 60: 717-28.

${ }^{4}$ Keech RV, Scott WE, Christensen LE: Adjustable suture strabismus surgery. J Ped Ophthal and Strab 1987, 24: 97-102.
${ }_{5}^{5}$ Jampolsky AL: Strabismus re-operation techniques. Trans Am Acad Ophthalmol Otolaryngol 1975, 79: 704-17.

${ }^{6}$ Fells P: The use of adjustable sutures. Trans Ophthalmol Soc UK 1981, 101: 279-83.

${ }^{7}$ Fells P: The treatment of non-comitant strabismus. In Documenta Ophthalmologica Proc Studies. Amsterdam: Junk 1982, 32: 197-207.

8 Fells P: Strabismus surgery under local anaesthetic: one stage technique using adjustable sutures. In: Ravault AP, Lenk M, eds. Trans of 5th International Orthoptic Congress. France: LIPS, 1983, 501-5. 